\title{
Novel Centralized Control Battery Operation, on Microgrids to Supply The Load Priority
}

\author{
Hartono Budi Santoso ${ }^{1}$, Wike Handini ${ }^{1}$, Rudy Setiabudy ${ }^{1}$, and Budiyanto ${ }^{1}$
}

\begin{abstract}
Priority loads, in micro grid is preferred load to always get the power supply. Battery function, in micro grid, in addition, functioning as a storage energy, it also serves as a stabilizer of network, due to intermittent of energy sources, both solar and from wind. As energy storage, battery is intended to supply energy when other sources of energy is not available. So far, the mechanism of battery operation, distributed on each generation, so that when operation standalone, battery capacity is not in optimal level. In this study, proposed, method of centralized control battery operation, which would regulate the use of battery operation, especially to supply the load priority. So that the power supply from the battery to the load priority, it would be optimal in optimal level when other sources are no longer, by utilizing parameters weather and load forecast.
\end{abstract}

Keywords $\longrightarrow$ Microgrid, Load priority, Centralized control battery, weather forecast and load forecast.

\section{INTRODUCTION}

$\mathrm{T}_{\mathrm{s}}^{\mathrm{h}}$ he increase in the penetration of distributed generation and the presence of multiple distributed generators in electrical proximity to one another have brought about the concept of the microgrid [1,2]. The concept of the microgrid was first proposed by the Consortium for Electric Reliability Technology Solutions (CERTS) in America; it is a new type of distributed generation network structure with a wide range of development prospects [3].

Microgrids comprise low-voltage distribution systems with distributed energy sources, storage devices, and controllable loads that are operated either islanded or connected to the main power grid in a controlled, coordinated way. In grid connected mode, the microsources act as constant power sources, which are controlled to inject the demanded power into the network[4]. During islanding, each distributed generation unit is able to balance power and share loads within the microgrid system [5].

The benefits of the microgrid, such as enhanced local reliability, reduced feeder losses, and local voltage support, providing increased efficiency using waste heat as combined heat and power, voltage sag correction, or providing uninterruptible power supply functions. The steady progress in the development of distributed power generation, such as microgrids and renewable energy technologies, are opening up new opportunities for the utilization of energy resources [6-7]. The topological change in the power system landscape is opening up possibilities to form micro-grids: localized groups of DGs, storages and loads that act as autonomous power systems with a single point of common coupling to the main electricity network. Battery energy storage units provide an added degree of freedom to a microgrid that allows time-shifting between the generation and use of energy. Microgrid energy storage elements are very similar to any other inverter-based source with the exception of bi-directional power flow capabilities. Having the ability to generate and accept power means

${ }^{1}$ Hartono Budi Santoso, Wike Handini, Rudy Setiabudy, and Budiyanto are with Departement of Electrical Engineering, Faculty of Engineering, Universitas Indonesia, Depok, Indonesia. E-mail: hartono@esi-labs.com; wike_handini@yahoo.com; rudy@eng.ui.ac.id; yan.budiyanto@yahoo.com. that the demand and the supply can be disparate by as far as the power capabilities of the energy storage unit allow [8]. To minimize the micro-grid operation cost or equivalently maximize the profit, and the decision variables are the charging and discharging power of the battery storage system for each time interval of the day, the micro-grid management schedules the battery for the day-ahead by taking into account the hourly electricity tariffs and the load and generation forecasts. [9].

Priority loads, in micro grid is preferred load to always get the power supply. Battery function, in micro grid, in addition, functioning as a storage energy, it also serves as a stabilizer of network, due to intermittent of energy sources, both solar and from wind. As energy storage, battery is intended to supply energy when other sources of energy is not available. So far, the mechanism of battery operation, distributed on each generation, so that when operation standalone, battery capacity is not in optimal level. In this study, proposed, method of centralized control battery operation, which would regulate the use of battery operation, especially to supply the load priority. So that the power supply from the battery to the load priority, it would be optimal in optimal level when other sources are no longer, by utilizing parameters weather and load forecast.

\section{DESCRIPTION OF WORK}

Microgrid system developed scheme can be seen in Figure 2. In the diagram of the system, the performance of microgrid is expected to be improved by applying a power-sharing application for each on / off GTI based on short-term load forecast data and estimated data based on the power that can be generated weather forecast data, in addition to solar radiation readings that point to estimates estimates of potential electrical power from solar panels. Overall this parameter, is used as the operating parameters of each generator on / off GTI on microgrid, to obtain optimum operating level.

In microgrid, each energy source, either from solar cells, wind and other energy sources, is all converted into electrical energy using suitable power converter circuit and form a distributed power generator network. The output of each inverter circuits is connected in parallel to supply the load at the same time. The inverter configuration in microgrid as shown in Figure 3 [10]. 
Inverter in the circuit can be on-off GTI. Each inverter will supply power according to power owned by the local load. If there is any excess power, it will be supplied to the network/grid. Meanwhile, if the inverter is lack of power, to meet the needs of local power, the grid will supply power to local load.

In islanding conditions or off grid, where there is no power from network, then it needs a control system that can manage the work of each inverter to be connected especially in relation to distribution of power that must be supplied by each inverters. Thus each inverters can supply power to other inverter loads that lack of power to supply to the load.

Control configuration that can be used in microgrid during islanding condition can be classified into two types, they are, using communication media to coordinate between inverter and without communication media. Load sharing method with communication media including, centralized control, master slave, average load sharing (ALS), circular chain control (3C) [11].

Equivalent circuit of distributed generator using master-slave control configuration during islanding condition can be seen in Figure 4 [11]. In the circuit above, an inverter works as voltage source that serves as temporary master while other inverters work as a current source that serve as slave.

In this operation mode, each current source, in form of GTI, should be able to set the amount of power that will be sent to network. This is because characteristics of GTI with its MPPT feature will transmit power as much as the existing power available in the source. Therefore it is necessary to do operation control mechanism of distributed generator during islanding condition.

Operations scheme of on/off GTI in three modes, they are: stand alone/off grid, connected to the network (ongrid) and the parallel between the two inverters during off grid condition. This experiment is using two $500 \mathrm{~W}$ on/off GTI and 2 x (4 x 100Wp) PV .

\section{A. Stand aloneloff grid Operation}

Power equation on a stand-alone inverter system can be described by the amount of power input from PV, $P_{p v}$ and the power needed by the load, $P_{L}$. Power amount generated by $\mathrm{PV}$ is,

$P_{p v}=V_{p v} . I_{p v}$

$I_{p v}=N I_{p v m}$

Where $V_{p v} \mathrm{PV}$ voltage and $I_{p v}$ is the output current of PV module, determined by the number of modules, $\mathrm{N}$ and output current each PV module, $I_{p v m}$. While the magnitude of the load expressed $P_{L}=V_{L} \angle \theta_{1} . I_{L} \angle \theta_{2}$.

The relationship between the power at the load against input power PV, $P_{L}=\eta P_{p v}$ where $\eta$ is the efficiency of PV power against the load, which is affected by the dissipation factor $\left(d_{f}\right)$ of inverter and duty cycle (D) of $\mathrm{dc}-\mathrm{dc}$ converter of inverter, so it can be concluded that,

$\eta=\left(1-d_{f}\right) D$

$P_{L}=\left(1-d_{f}\right) D P_{p v}$

$\mathrm{D}$ parameteris used to arrange so that the PV power is sufficient with the power needs of the load, the amount is $0<\mathrm{D} \leq 1$. The above equation is valid if the battery condition is full or the system does not use a battery and $P_{L}<P_{p v}$. If the inverter is connected to the battery, the following equation will apply:

$$
\begin{aligned}
& \text { For, } P_{L}<P_{p v} \\
& P_{p v}=P_{b}+P_{d}+P_{D}+P_{L} \\
& P_{i n v}=P_{p v}-P_{b} \\
& P_{L}=P_{i n v}-\left(P_{d}+P_{D}\right)
\end{aligned}
$$

The above equation applies at the level of battery power $\left(P_{l b}\right)$ at the time, $P_{l b}<P_{b \max }$ (maximum power level of the battery), when $P_{b}=0$, then the inverter input power, $P_{i n v}=P_{p v}$. The amount of $P_{b}$ indicates battery charging, $P_{d}$ inverter power dissipation, and $P_{D}$ inverter input power are not supplied to the load, when $\mathrm{D}<1$.

$P_{d}=d_{f} P_{i n v}$

$P_{D}=\left(1-d_{f}\right)(1-D) P_{i n v}$

from equation 5 shows that the amount of PV power that used to supply the battery is determined by how much the rest of the PV power after being used to supply the load.

For $P_{L}>P_{p v}$

$P_{i n v}=P_{p v}+P_{b}$

$P_{L}=\left(1-d_{f}\right) D P_{i n v}$

From equation 7 shows that at the current load is greater than the power generated by the PV then PV power plus battery power is used to supply the load.

\section{B. On grid Operation}

Power equation for each inverter when connected to a network is expressed by the following equation,

For $P_{L}<P_{p v}$

$P_{p v}=\left(P_{L}+P_{d}+P_{g}\right)$

For $P_{L}>P_{p v}$

$P_{L}=\left(P_{p v}+P_{g^{-}} P_{d}\right)$

In Equation 9, when the power on the load is smaller than the input power of PV and by using MPPT mechanism PV will produce maximum power, so that $\mathrm{D}$ $\cong 1$, it means that almost all of the PV power is distributed to local load and grid. In this condition, the inverter works as a current source. In this configuration connection to the battery is removed. This is because if the battery is connected to the circuit then battery power will also supply to grid until power supplied reach maximum power capacity of the inverter. Meanwhile, when the amount of PV power is smaller than the load, equation 10, then the amount of power delivered to the load is supplied from PV and networks. When more than one inverter is connected to the network then the amount of power supplied to the grid applies the following equation,

$P_{g}=\left(P_{p v 1}+P_{p v 2}+\ldots+P_{p v n}\right)-\left(P_{L 1}+P_{L 2}+\ldots+P_{L n}+P_{d 1}\right.$ $\left.+P_{d l}+\ldots+P_{d n}\right)$

If $P_{g}$ is negative then the grid will supply power to the inverter network, because of the PV power is not enough to fulfill the needs of the load. Meanwhile, if $P_{g}$ is positive it means that there is excess power from the PV and will be distributed to the grid.

\section{Operation of Parallel Inverter in off grid/Islanding condition}

Power equation during islanding conditions is where two inverters are connected in parallel with the master slave configuration. One inverter works as a master and serve as a reference for another inverter operation that 
works as a slave. In this condition it will apply the following equation,

$$
\begin{aligned}
& P_{L 1}+P_{L 2}<P_{p v 1}+P_{p v 2} \\
& \left(P_{L 1}+P_{L 2}\right)=\left(1-d_{f 1}\right) D_{1} P_{p v 1}+\left(1-d_{f 2}\right) D\left(P_{p v 2}-P_{b 2}\right) \\
& =\left(1-d_{f 1}\right) D_{1} V_{p v 1} N I_{p v l m}+\left(1-d_{f 2}\right) D\left(P_{p v 2}-P_{b 2}\right) \\
& P_{L 1}+P_{L 2}>P_{p v 1}+P_{p v 2} \\
& \left(P_{L 1}+P_{L 2}\right) \quad=\left(1-d_{f 1}\right) D_{1}\left(V_{p v 1} N I_{p v 1 m}+P_{b 1}\right)+(1- \\
& \left.d_{f 2}\right) D\left(P_{p v 2}+P_{b 2}\right)
\end{aligned}
$$

On condition $P_{L 1}+P_{L 2}<P_{p v 1}+P_{p v 2}$ shown on equation 12 , to make the power that is supplied from each generation to meet the load power needs, without going over-supply, particularly from the inverter that serves as a slave, then the amount of power distributed to the load carried with a set number of PV modules that are connected to the inverter $(\mathrm{N})$ by setting the switch that connects the PV circuit.

While, on the condition $P_{L 1}+P_{L 2}>P_{p v 1}+P_{p v 2}$ from equation 12 shown that there is battery power on the inverter parameter 1, this will happened if the PV power reach its maximum level (the whole $\mathrm{PV}$ is already connected) but it can not accommodate load power needs, so power from battery inverter 1 will also supply power to the loads.

In the parallel inverter testing in isolated conditions, the measurement results show that both inverters can work in parallel, as shown in Table 1.

The test results showed that during off-grid condition, each inverter will work as a standalone inverter. The first test assumed that the battery in inverter 2 is in full condition, therefore in this test the battery is not connected to inverter 2. As shown from $94.34 \mathrm{~W}$ of power that should be generated by the inverter 2 is only used $69.31 \mathrm{~W}$ is only about $73.47 \%$ of power used to supply load. Moreover, because power from PV required to supply load on inverter 1 is not sufficient then the power shortage is supplied from the battery.

By parallelizing both inverters, it shows that at the power needs in inverter 1 is supplied by inverter 2 which acts as the master and inverter 1 as slave. Power absorption in inverter 2 performed optimally. When the power from inverter 1 is reduced, the excess power will flow into the battery. In this test, the battery is connected back to the master. In addition, there is a change in power flow direction from the inverter 1 where the excess of power in inverter 1 is supplied to inverter 2 .

When there is an increase in input power in PV where the power of inverter 1 exceeds power needed by inverter $2 /$ master causing a reverse current on inverter 2 , protection on inverter 2 disconnect parallel connection on both inverters, as shown in Figure 8 (a), so that the configuration change to stand-alone operation. Through the reconfiguration of PV circuit by reducing the amount of PV panels on inverter 1, then power equilibrium can be achieved again so that both inverters can work in parallel. Synchronous condition when both inverter work in parallel shown in Figure 8 (b).

When power on the inverter 2 is greater than power on inverter 1 then part of the power inverter 1 is supplied to inverter 2 and power shortage will be taken of battery power. But when PV power increased through reconfiguration of $\mathrm{PV}$ circuit, by connecting all PV1 panel, then it shows in Table 4 that some of the excess power of inverter 1 is used to supply power to inverter 2 and excess power in the inverter 2 is stored to battery. Test circuit is shown in Figure 9.

\section{Proposed POWER SHARING METHOD IN CENTRALIZED CONTROL OF MICROGRIDS}

Proposed method, controls power sharing between plants especially during islanding conditions and the battery operation mode is intended to obtain a longer operating time than the overall microgrid system. With this method the performance is expected to be better microgrid system which during operation the battery does not need load shedding, in particular the priority load.

The development of power sharing method is done through simulation three inverter parallel operation in islanding condition. Simulations carried out in three modes of operation, namely, stand alone operation during islanding conditions, parallel operation during islanding conditions.

Parallel operation performed two methods of power sharing, equalizing output power, and equalizing battery level. At equalizing output power, the overall output power inverter operates share equally, while the battery level equalizing mode, the overall level of the battery inverter battery operated at relatively the same level. Of the three methods are then conducted test operations using the data simulated solar radiation estimates and estimated load. Based on these data by planning, operation of the third inverter. Device simulation specification, is as follows on Table 2.

The final results of simulation, is expected to obtain a third inverter continuous operation, without having to do a load disconnection or inverter inability to supply the load. At the end of the simulation, the battery level is expected to be achieved, approaching the optimal level of the battery. Simulation data starts at $18.00 \mathrm{pm}$ up to 24 hours ahead.

Based on these data do simulated operation in three modes of operation that is:

a. Stand alone

b. equalizing output power inverter

c. equalizing Battery level

Estimates of radiation are like shown in Figure 10. While estimates of the load simulation data as shown in Figure 11.

In standalone operation mode when the islanding inverters, each working independently supply the local loads. In this mode the inverter output power is equal to the load to be supplied. In this operation mode of the inverter first seen at 4 and 5 am is not capable of supplying power to the load, this happens because the power in the battery backup is up before the sun rises at $6 \mathrm{am}$. When viewed from the level of each battery inverter battery level reaches a maximum. The simulation shows the output power of the inverter and the battery level as shown in Figure 12 and 13.

In the operation mode of inverter output power equalizing, each inverter works with any inverter output power mode which is inclined at an average of a third of the total power inverter, so every inverter carry the same amount of power. As shown in Figure 11. When there is an inverter is no longer capable of supplying power, for running out of battery power, then the remaining two inverters, if possible, will supply the total power that 
must be supplied to the third inverter. If unable to meet the required power, it will be a load termination.

In this mode looks though the inverter is no longer supplying power to the inverter power but is still able to be supplied by the remaining two power inverters in the inverter can still work for getting power supply from the two remaining inverters. It looks at though the inverter 2 hours 3 to 5 hours already inverter output power $=0 \mathrm{~W}$, but the load on the inverter can still be supplied power from the two remaining inverters. While the inverter 3 at 5 am The dead load on inverter is no longer able to power supplied from the power inverter 1 because there is no longer sufficient to supply the load inverter 3 . Consideration termination load on inverter 3 due to the power left in the inverter 1 just enough to supply power to the inverter 1 and inverter 2 . The results of the simulation mode of operation is shown in figure 14, 15 and 16.

In operating mode, battery level equalizing, all operating system will try and keep the level of the third inverter batteries at the same nominal, so that at any time can be achieved any condition remain capable of supplying power inverter. This behavior is shown in the graph in which the battery level at some time third-level inverter has the same battery. When the battery level is reached the same result each inverter also supplies the same power. In this operation mode the third inverter capable of supplying the entire load should be supplied as the load estimates. However, the magnitude of the inverter itself the power output is not equal to the load that should have been supplied.

This is due to the mechanism of power sharing between inverters. Also at the end of the third inverter simulation reached the maximum level of the battery in position. The simulation results can be seen in Figure 17 and 18.

Based on the simulation results it can be seen that the application of the method of sharing power is based on equalizing level of the battery gives a better performasi where all the load can still be served by the third event of termination of the inverter without load and battery maximum level reached at the end of the simulation.

\section{CONCLUSION}

Based on simulation results, it can be seen that, application-sharing method based on the similarity level of battery power, giving better performance, in which all the load, still can be served by a third inverter, without any load shedding, and maximum battery level is reached at the end of the simulation

\section{REFERENCES}

[1]. R. Lasseter, A. Akhil, C. Marnay, J. Stephens, J. Dagle, R. Guttromson, A. Meliopoulos, R. Yinger, J. Eto, White paper on Integration of Consortium Energy Resources. The CERTS MicroGrid Concept, CERTS, Rep. LBNL-50829, 2002.

[2]. MICROGRIDS: Large Scale Integration of Micro-Generation to Low Voltage Grids, EU Contact ENK5-CT-2002-00610, Technical Annex, 2002.

[3]. W. Deng, W. Pei, Z. Qi, "Impact and improvement of distributed generation on voltage quality in micro-grid", 3rd International Conference on Electric Utility Deregulation and Restructuring and Power Technologies, pp. 1737-1741, 2008.

[4]. A. A. Salam, A. Mohamed and M. A. Hannan, "TECHNICAL CHALLENGES ON MICROGRIDS", ARPN Journal of Engineering and Applied Sciences, VOL. 3, NO. 6, DECEMBER 2008, pp. 64-69

[5]. J. A. Pecas Lopes, C.L Moreira, F.O.Resende. 2005 Microgrids blackstart and islanding operation in Proc.15th PSCC, Liege, Belgium,

[6]. R.H. Lasseter, "Microgrids", IEEE Power Engineering Society Winter Meeting, Vol. 1, pp. 305-308, 2002.

[7]. C. Marnay, G. Venkataramanan, "Microgrids in the evolving electricity generation and delivery infrastructure", IEEE Power Engineering Society General Meeting, pp. 18-22, 2006.

[8]. Robert Lasseter, Micah Erickson, "Integration of BatteryBased Energy Storage Element in the CERTS Microgrid", CERTS, University of Wisconsin-Madison, October 27, 2009

[9]. Pukar Mahat, Jorge Escribano Jiménez, Eloy Rodriguez Moldes, Sandra Iren Haug,Ireneusz Grzegorz Szczesny, Karl Eide Pollestad, Luminita Cristiana Totu, "A Micro-Grid Battery Storage Management" Proceedings of the IEEE PES General Meeting 2013, IEEE Press, 2013

[10]. Chien-Liang Chen, Yubin Wang, Jih-Sheng (Jason) Lai, Yuang-Shung Lee, dan Daniel Martin, "Design of Parallel Inverters for Smooth Mode Transfer Microgrid Applications", IEEE TRANSACTIONS ON POWER ELECTRONICS, VOL. 25, NO. 1, JANUARY 2010

[11]. Josep M. Guerrero, Lijun Hang, dan Javier Uceda, "Control of Distributed Uninterruptible Power Supply Systems", IEEE TRANSACTIONS ON INDUSTRIAL ELECTRONICS, VOL. 55, NO. 8, AUGUST 2008

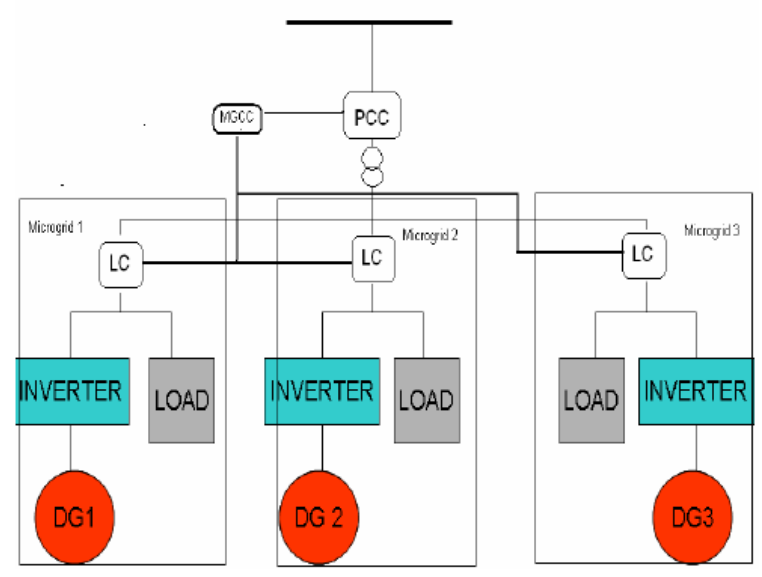

Figure 1. Diagram of microgrid system 


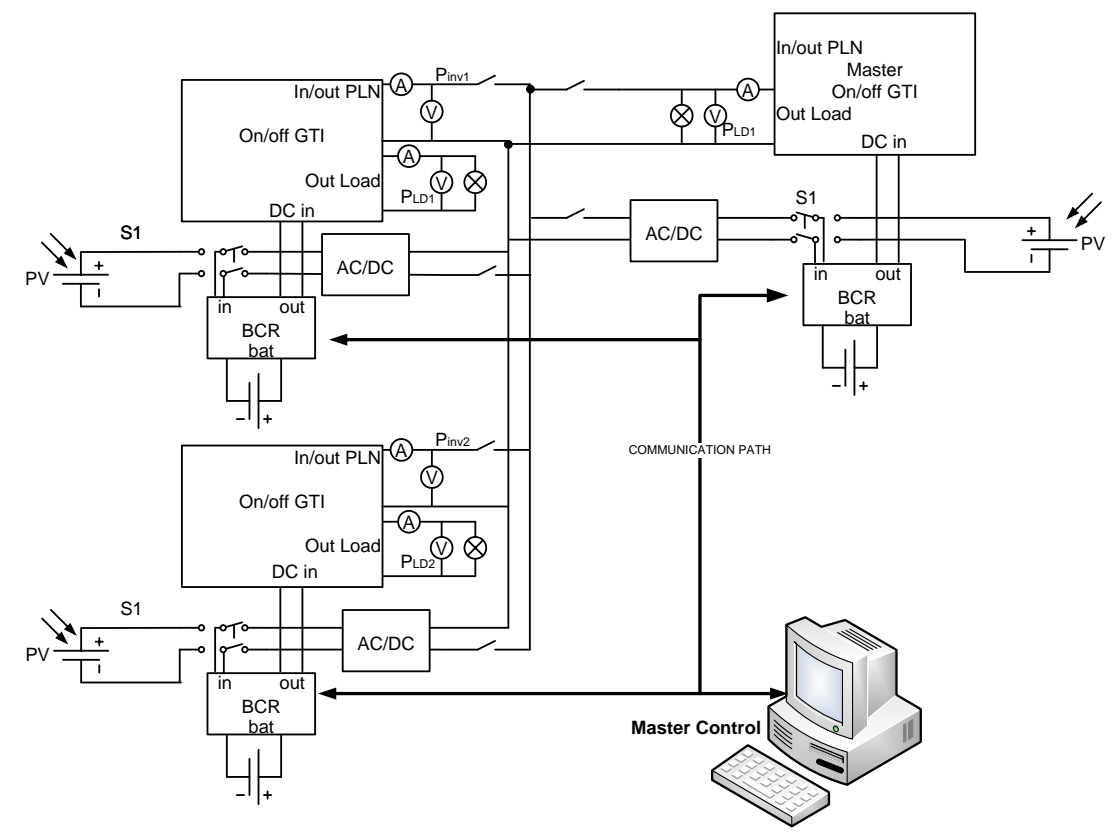

Figure 2. Diagram microgrid system using on / off GTI with power sharing control system during islanding conditions

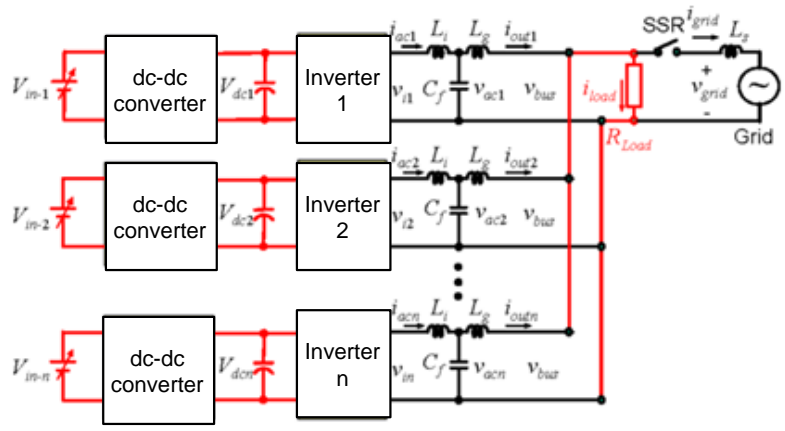

Figure 3. Configuration of distributed electric network

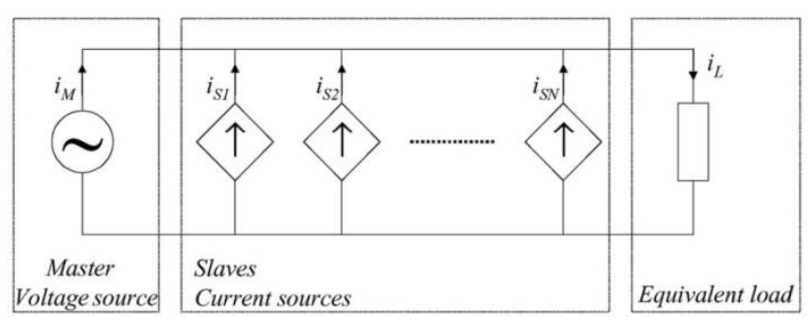

Figure 4. Equivalent circuit of parallel inverters in distributed generator

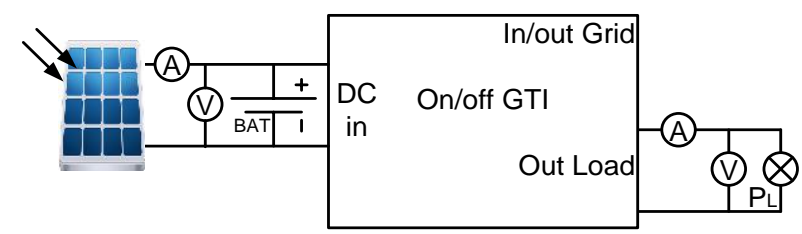

Figure 5. Circuit of stand alone/off grid inverter

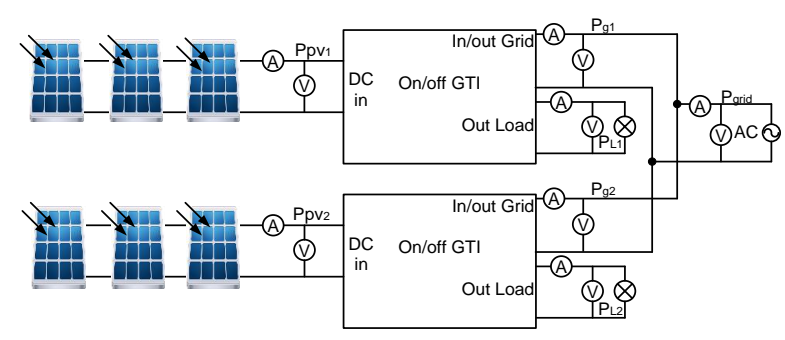

Figure 6. Circuit of on grid inverter

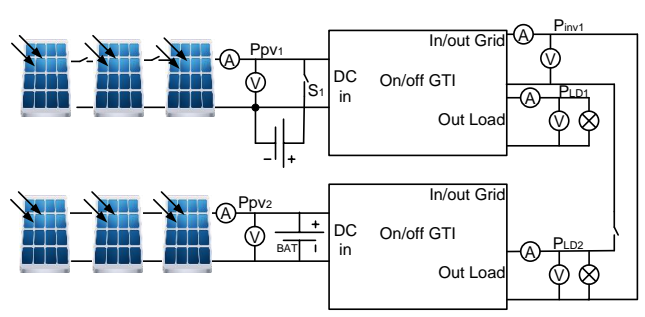

Figure 7. Circuit of parallel inverter in off grid/islanding

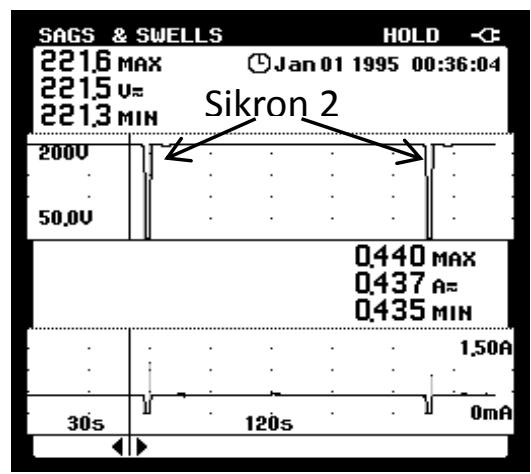

(a)

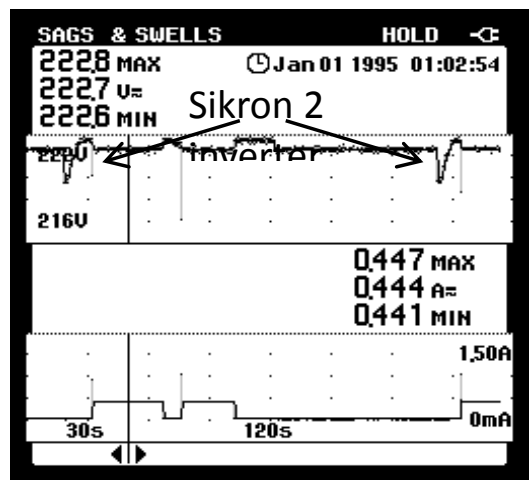

(b)

Figure 8. (a). Unstable condition of parallel 2 inverter due to reverse current (b). Synchronous condition of 2 stable invertere and achievedstability due to power arrangement 


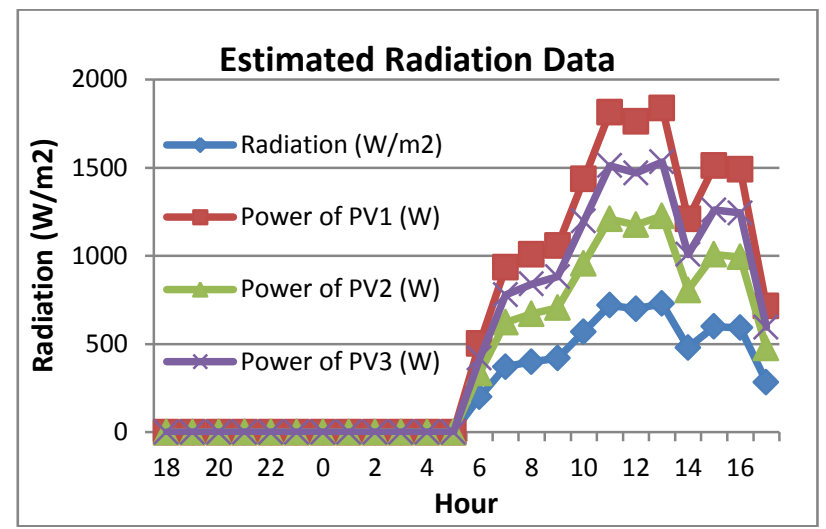

Figure 10. Data simulated radiation forecasts

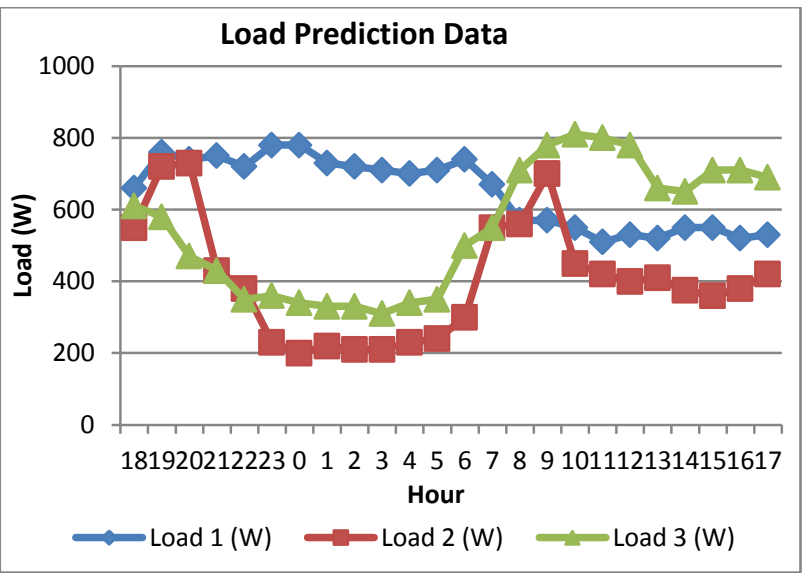

Figure 11. Simulation data load estimates

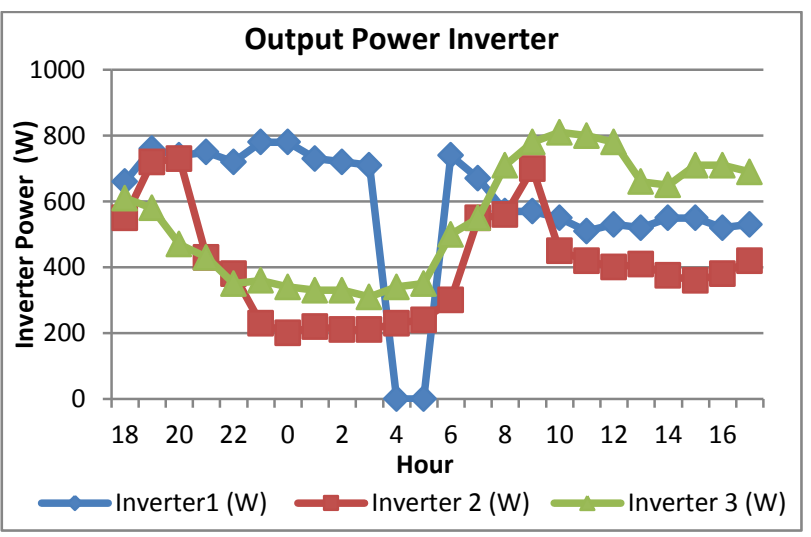

Figure 12. Graph output power of each inverter

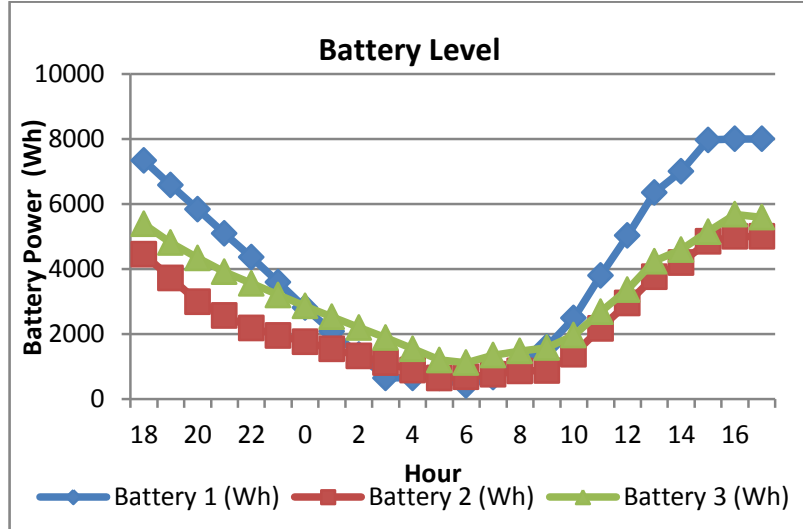

Figure 13. Battery Power Level

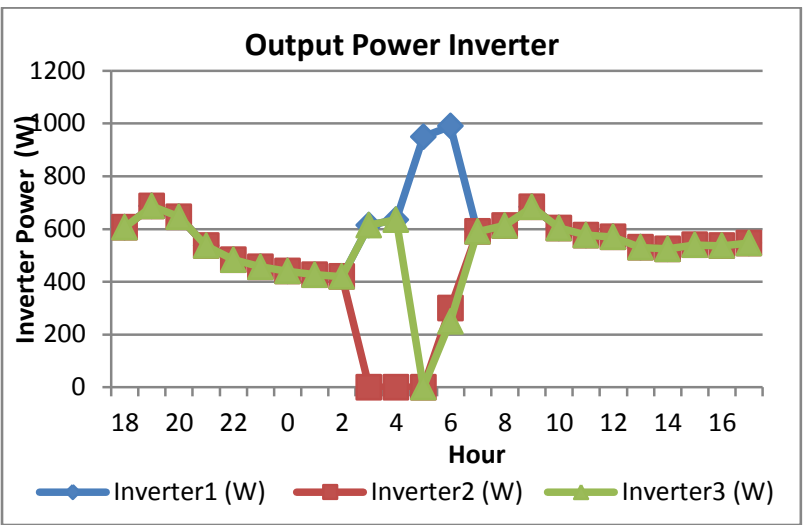

Figure 14. Inverter output power

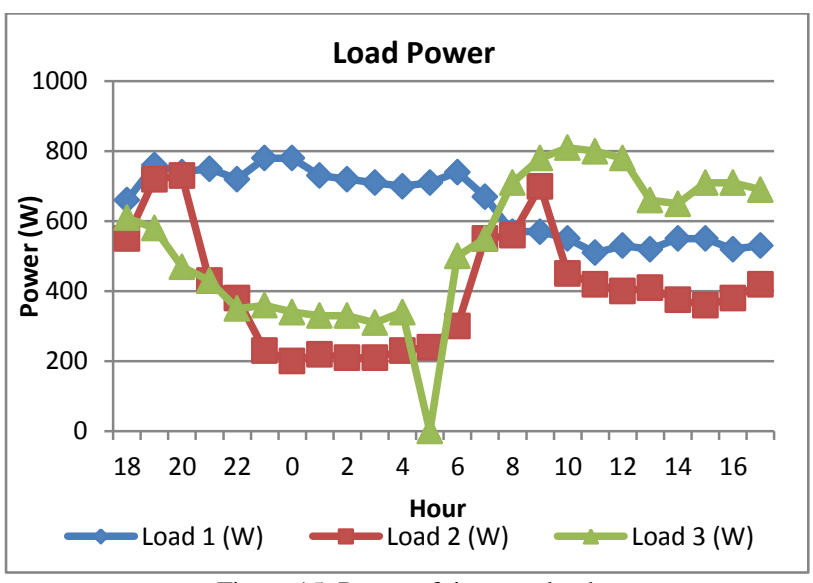

Figure 15. Power of inverter load

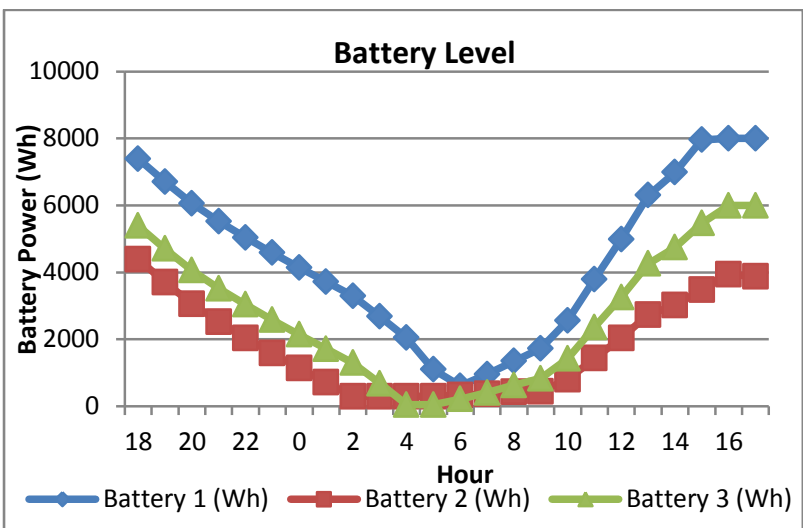

Figure 16. Battery level

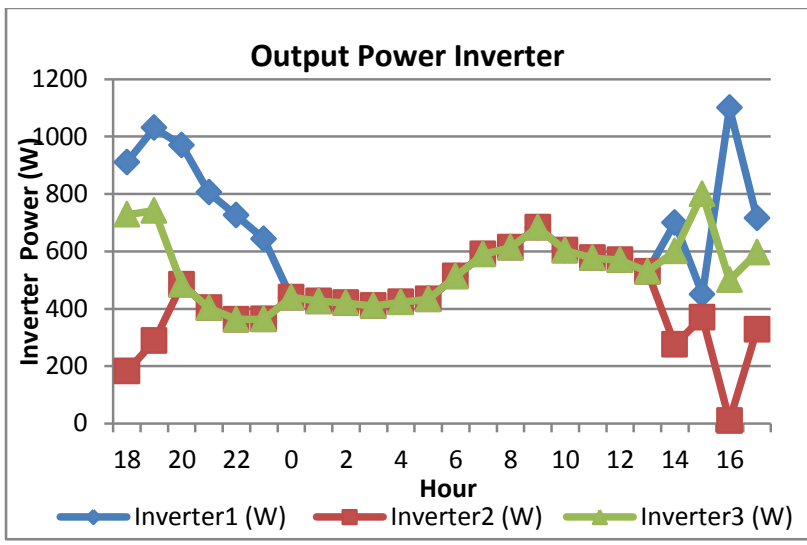

Figure 17. Output power inverter 


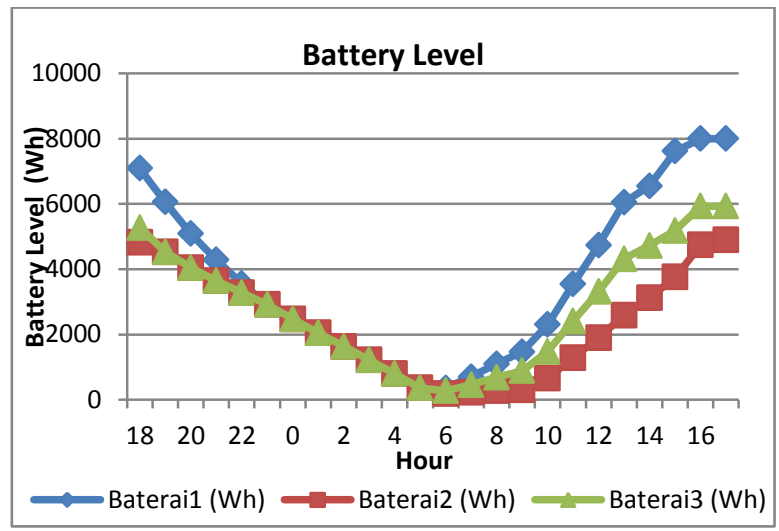

Figure 18. battery level

TABLE 1.

PARALLEL 2 ON/OFF GTI IN OFF GRID CONDITION

\begin{tabular}{cccccrrrrr}
\hline \hline \multirow{2}{*}{ Rad } & \multicolumn{1}{c}{ Num. of PV } & \multicolumn{2}{c}{$\mathrm{PV}(\mathrm{DC})$} & \multicolumn{2}{c}{ BATT (DC) } & \multicolumn{2}{c}{ INV1(AC) } & \multicolumn{2}{c}{ LOAD (AC) } \\
& $\mathrm{PV}_{1}$ & $\mathrm{PV}_{2}$ & $\mathrm{P}_{1}(\mathrm{~W})$ & $\mathrm{P}_{2}(\mathrm{~W})$ & $\mathrm{P}_{1}(\mathrm{~W})$ & $\mathrm{P}_{2}(\mathrm{~W})$ & $\mathrm{P}_{1}(\mathrm{~W})$ & $\mathrm{P}_{1}(\mathrm{~W})$ & $\mathrm{P}_{2}(\mathrm{~W})$ \\
\hline 588 & 4 & 4 & 94,34 & 69,31 & 14,96 & 0 & 0 & 56,7 & 14,8 \\
579 & 4 & 4 & 88,82 & 88,35 & 0 & 0 & $-20,95$ & 56,7 & 14,8 \\
576 & 4 & 4 & 88,69 & 88,67 & 0 & 15,68 & 9,89 & 25,5 & 14,8 \\
587 & 4 & 4 & 78,10 & 94,25 & 0 & 26,85 & 0 & 25,5 & 14,8 \\
591 & 3 & 4 & 70,98 & 94,65 & 0 & 20,13 & $-7,12$ & 25,5 & 14,8 \\
557 & 3 & 4 & 62,66 & 83,54 & 0 & $-30,5$ & $-4,74$ & 14,8 & 56,7 \\
601 & 4 & 4 & 95,53 & 95,52 & 0 & 14,36 & 28,13 & 14,8 & 56,7 \\
\hline \hline
\end{tabular}

TABLE 2.

DEVICE SIMULATION SPECIFICATION

\begin{tabular}{cccc}
\hline \hline & Num. of PV & $\begin{array}{c}\text { Battery } \\
\text { Capacity } \\
(\text { Wh })\end{array}$ & $\begin{array}{c}\text { Inverter } \\
\text { Power (W) }\end{array}$ \\
\hline Inverter 1 & 12 & 8000 & 1200 \\
Inverter 2 & 8 & 5000 & 1000 \\
Inverter 3 & 10 & 6000 & 1000 \\
\hline \hline
\end{tabular}

